\title{
Traverse Group Reservoirs in the Michigan Basin: A Second Look
}

Peter Voice and William B. Harrison III

Department of Geological and Environmental Sciences, Michigan Geological Survey and Michigan Geological Repository for Research and Education Western Michigan University

Abstract: Traverse Group reservoirs have been a prolific source of hydrocarbons in the Michigan Basin since the 1930's. Early exploration targeted structural traps in these relatively shallow reservoirs (300 to 900 meters). The reservoirs in these fields consists of dolomitized, vuggy carbonates sealed by argillaceous and organic shales of the overlying Antrim Shale.

The Traverse Group in the subsurface of Michigan includes the argillaceous shales of the Bell Shale and shales, dolomites and limestones of the Traverse Limestone. The facies of the Traverse Limestone reflect a shallow water carbonate bank present over much of the Lower Peninsula of Michigan. Facies include grainy oolitic and skeletal sand shoals, patch reefs and reef-associated rubble, muddy lagoonal carbonates, and open shelf deposits consisting of interbedded tempestites and bioturbated, cherty carbonates. Overlying the Traverse Limestone are argillaceous carbonates and dolomitic shales of the Squaw Bay Formation. The contact between the Traverse Limestone and the Squaw Bay Formation is a hardground with pyrite mineralization marking a period of relative sea level rise in the basin. The Squaw Bay Formation was deposited in the outer shelf under more reducing conditions. Up section, the Squaw Bay Formation becomes more argillaceous and exhibits higher gamma ray signatures. This zone transitions into the overlying Antrim Shales.

In productive reservoirs, dolomitization preceded up to the Squaw Bay Formation, which acted as a partial seal to these fluids. Dolomitization generated significant secondary porosity including vuggy and intercrystalline porosity (up to $12 \%$ in the Smith-Gerard \#1). Grainy carbonates (reef rubble; skeletal, pelletal and oolitic sands) provided permeable pathways for dolomitizing fluids to migrate through the Traverse Limestone if not cemented early.

Historic Production in Traverse Group reservoirs through 1986 was 108 million barrels of oil. Renewed interest in overlooked hydrocarbons is already driving exploration and speculation on the underlying Dundee-Rogers City Formations. These Middle Devonian Reservoirs were exploited prior to modern advances in technology and geologic principles - perhaps it is time to look at Traverse Group reservoirs again as well!

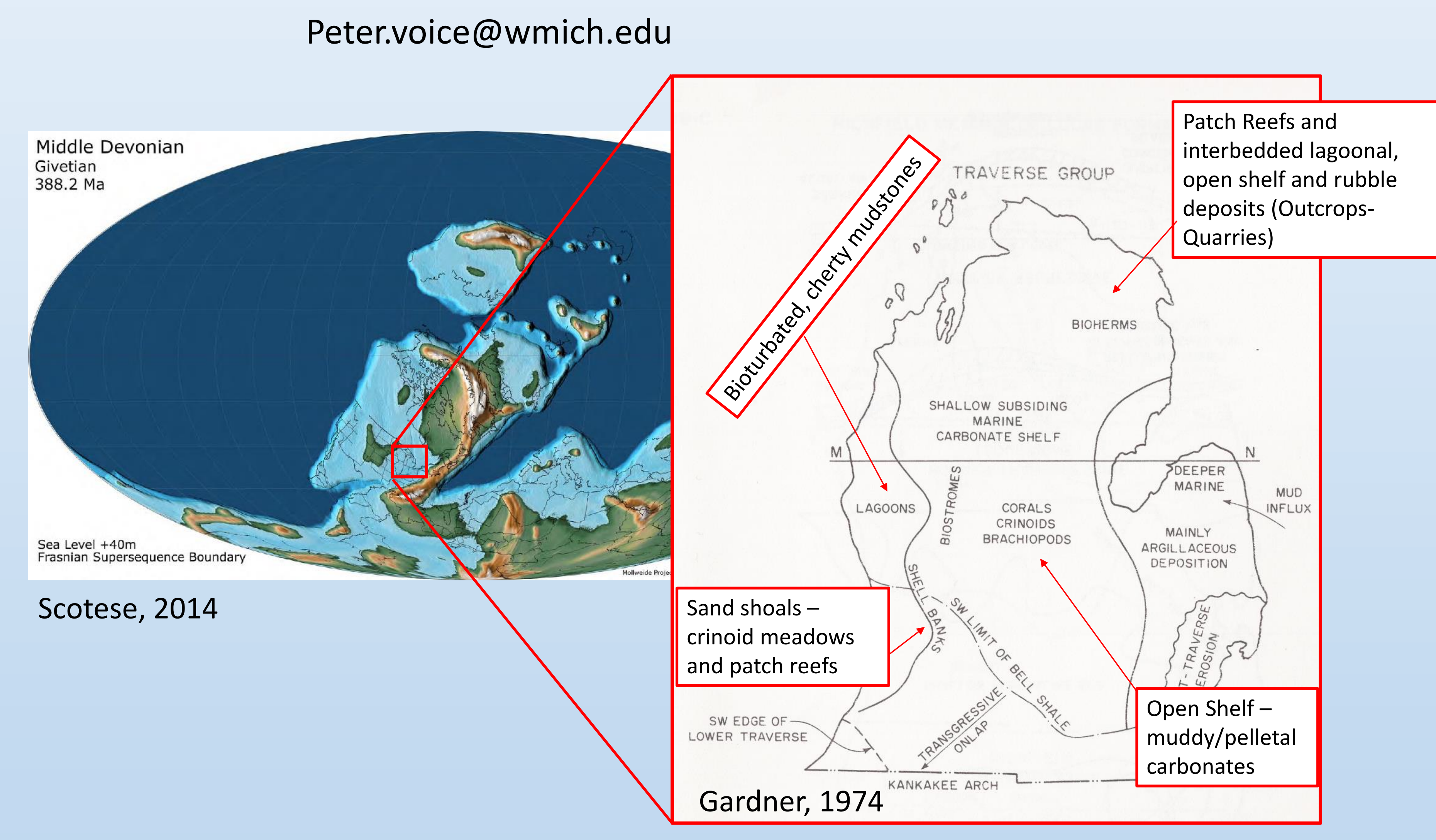

Figure 1: The Michigan Basin was located in the Tropics during the Middle Devonian. During this interval, the Michigan Basin was a shallow marine intracratonic basin. The Traverse Group consists of lagoonal and open shelf carbonates in the Lower Peninsula of Michigan.

\section{NW MI: \\ Antrim Shale \\ Jordan River Formation \\ Whiskey Creek Formation

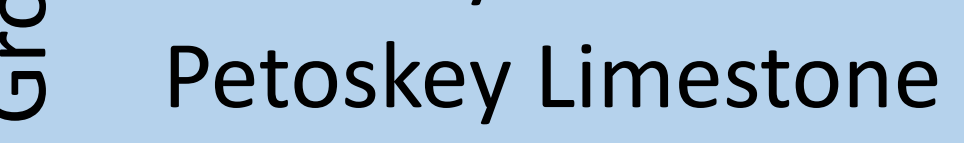 \\ $\circlearrowleft$ Charlevoix Limestone \\ त्ञ Gravel Point Formation Bell Shale}

Rogers City Formation
NE Mi:

Antrim Shale

Squaw Bay Formation

Thunder Bay Formation Potter Farm Formation

Norway Point Formation

글 Four Mile Dam Formation

IV Alpena Limestone

ڤ Newton Creek Limestone

$\bar{\nu}$ Genshaw Formation

常 Ferron Pt. Formation

Rockport Quarry Limestone Bell Shale

Rogers City Formation

\section{Subsurface:}

Antrim Shale

Squaw Bay Formation

글 Traverse Limestone

Bell Shale

Rogers City Formation

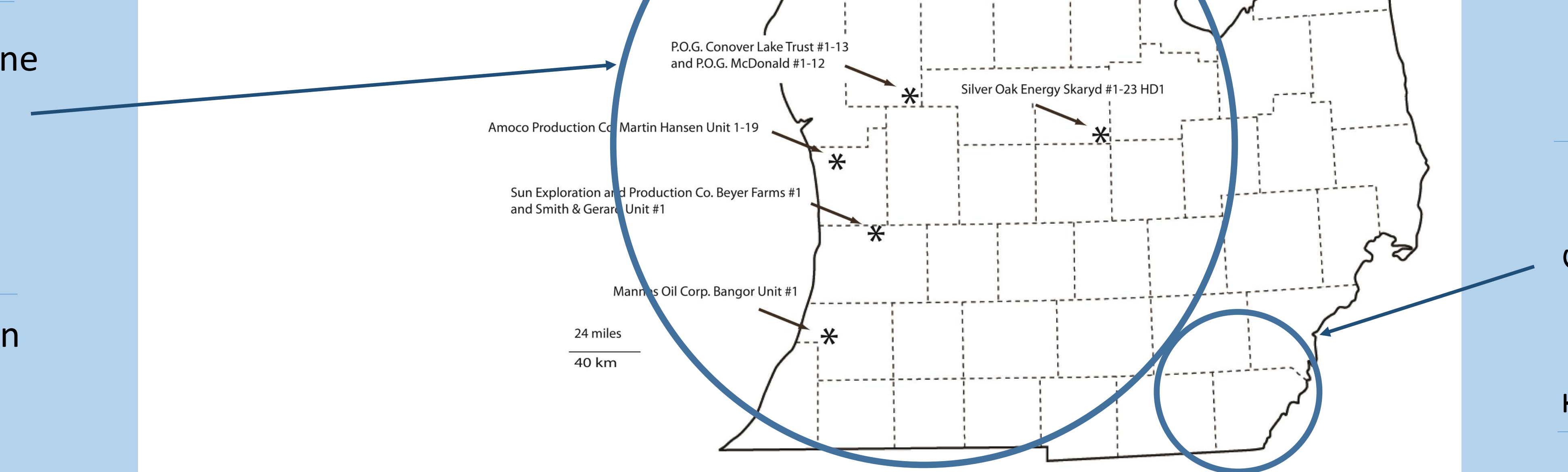

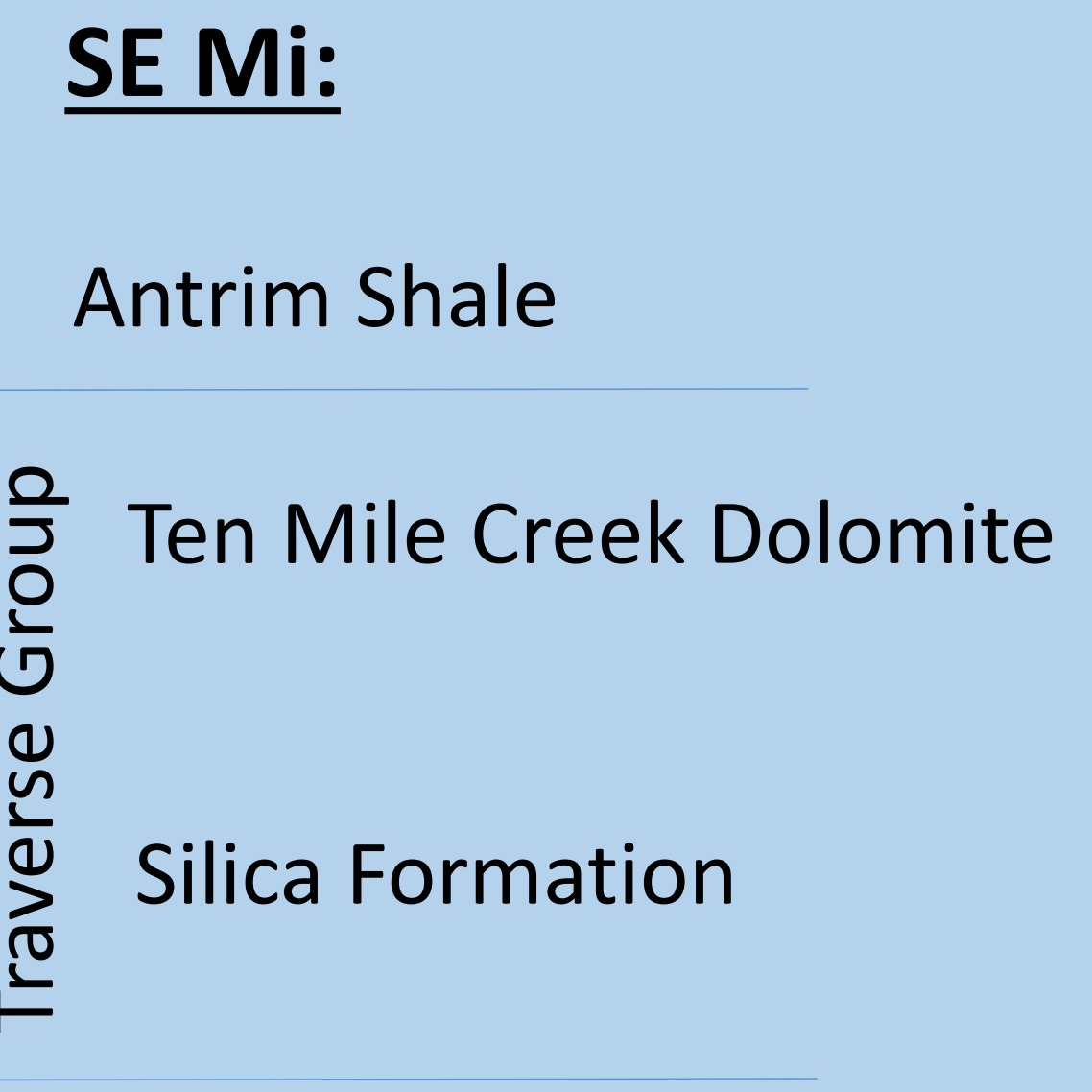

Dundee Limestone

Figure 2: Stratigraphic Nomenclature for the Traverse Group in the Lower Peninsual (compiled from Catacosinos et al., 2001, Ehlers and Kesling, 1970, Kesling et al., 1974, and Kesling and Chilman, 1975). The Traverse Group is the shallow subcrop and outcrop in the northeastern, northwestern and southeastern corners of the Lower Peninsula. The difficulty of correlating the Traverse Group through the basin has led to the proliferation of terms. In the subsurface, the drillers have simplified the nomenclature to a lower shale (Bell Shale) and an upper mixed carbonate-shale interval (Traverse Limestone). Note that the Squaw Bay Formation in older publications is referred to as the Traverse Formation.

The locations marked with asterisks on the map are wells used in this study to identify and describe facies in the upper Traverse Limestone. The marked wells have core in the upper 10 to $40 \mathrm{ft}$ ( 3 to $12 \mathrm{~m}$ ) and in many cases the contact with the overlying Squaw Bay Formation. 


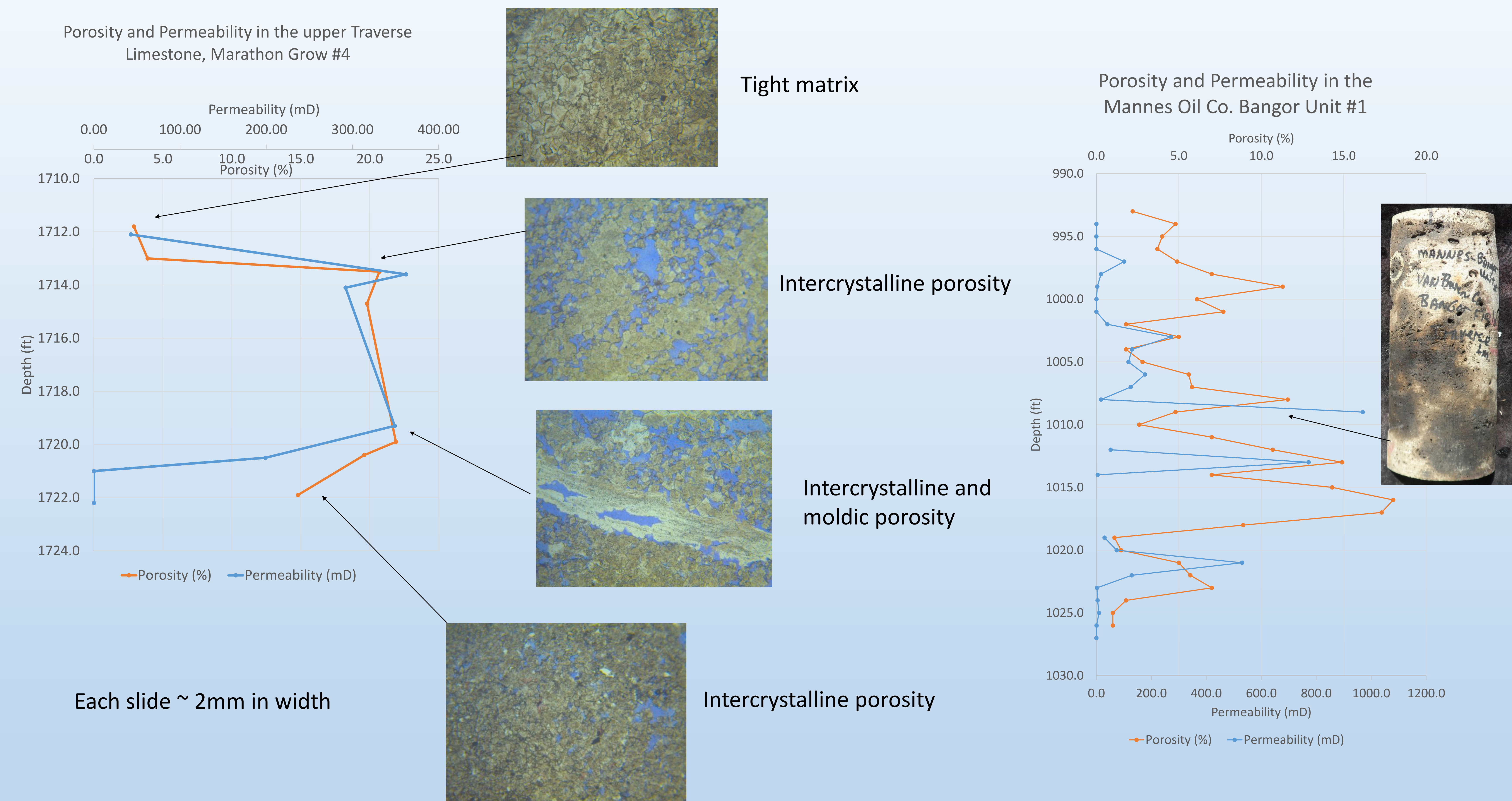

Figure 9: Porosity and Permeability trends in the Marathon Grow \#4 (Westbranch Field, Ogemaw Co., PN: 28399). The most porous interval is two feet below the contact with the Squaw Bay Formation. Porosity includes both intercrystalline and moldic porosity.

Figure 10: Porosity and Permeability trends in the Mannes Oil Co. Bangor Unit \#1 (Van Buren County, PN: 33749). The Traverse Limestone is again both porous and permeable near the contact with the Squaw Bay Formation (at 993'). Core photograph exhibits oil staining from a sample at $1008^{\prime}$.

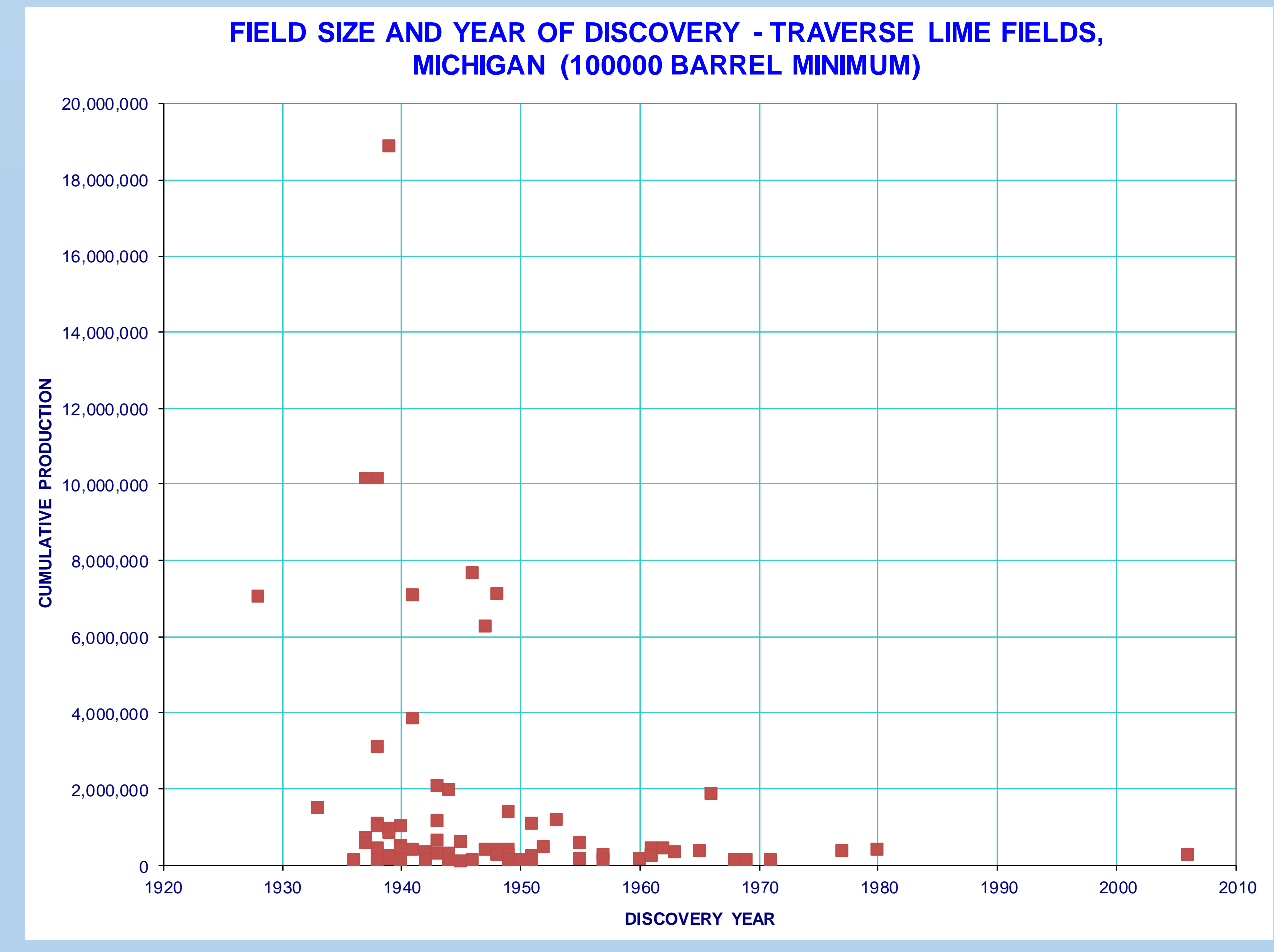

Figure 11: Traverse Limestone fields are old - most were discovered prior to revolutions in geophysical mapping of reservoirs (both seismic and wireline log data) and stratigraphy (facies models and sequence stratigraphy). The early discovery of these fields was from extensive drilling and structural mapping - which identified many of the larger Traverse fields.
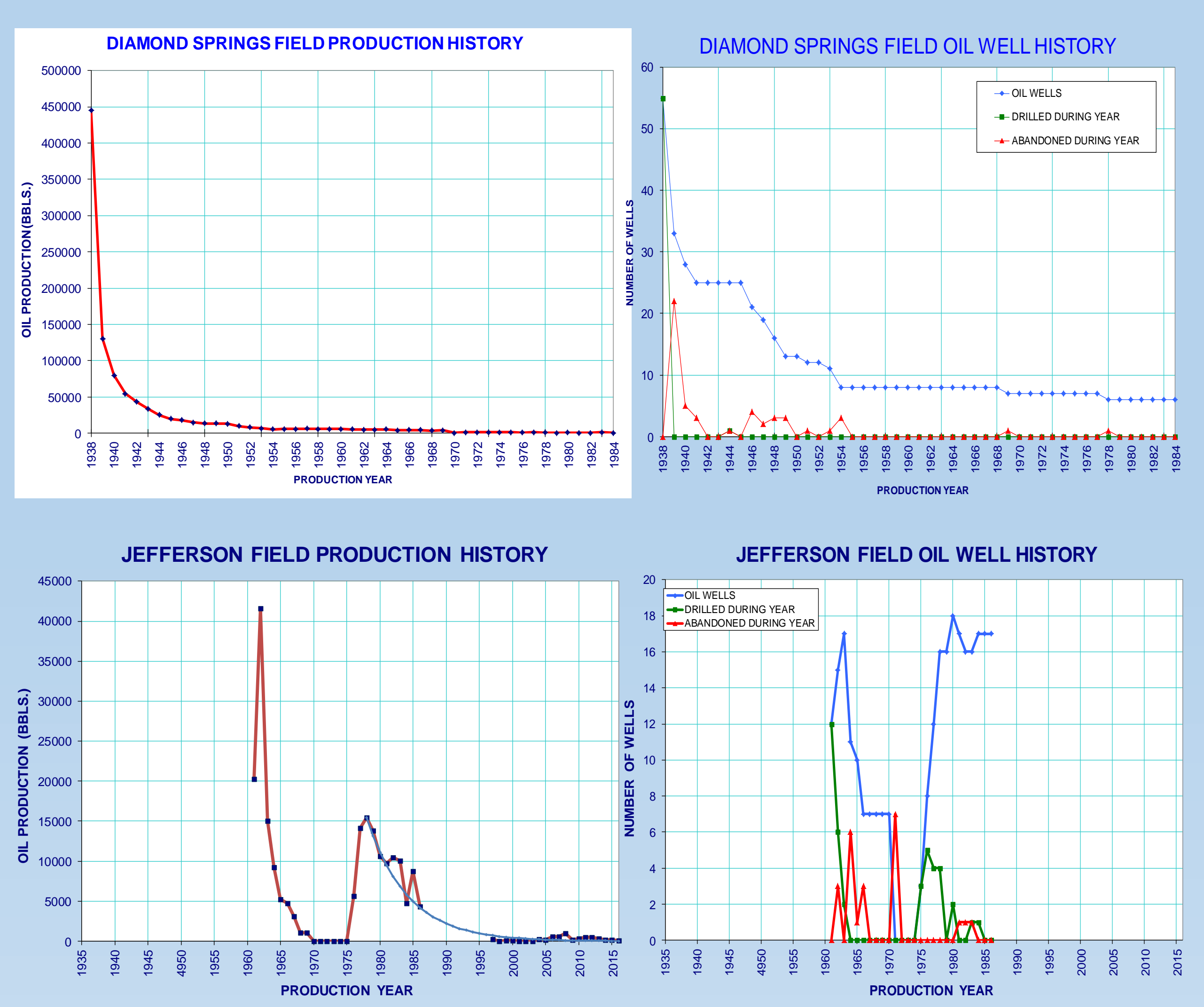

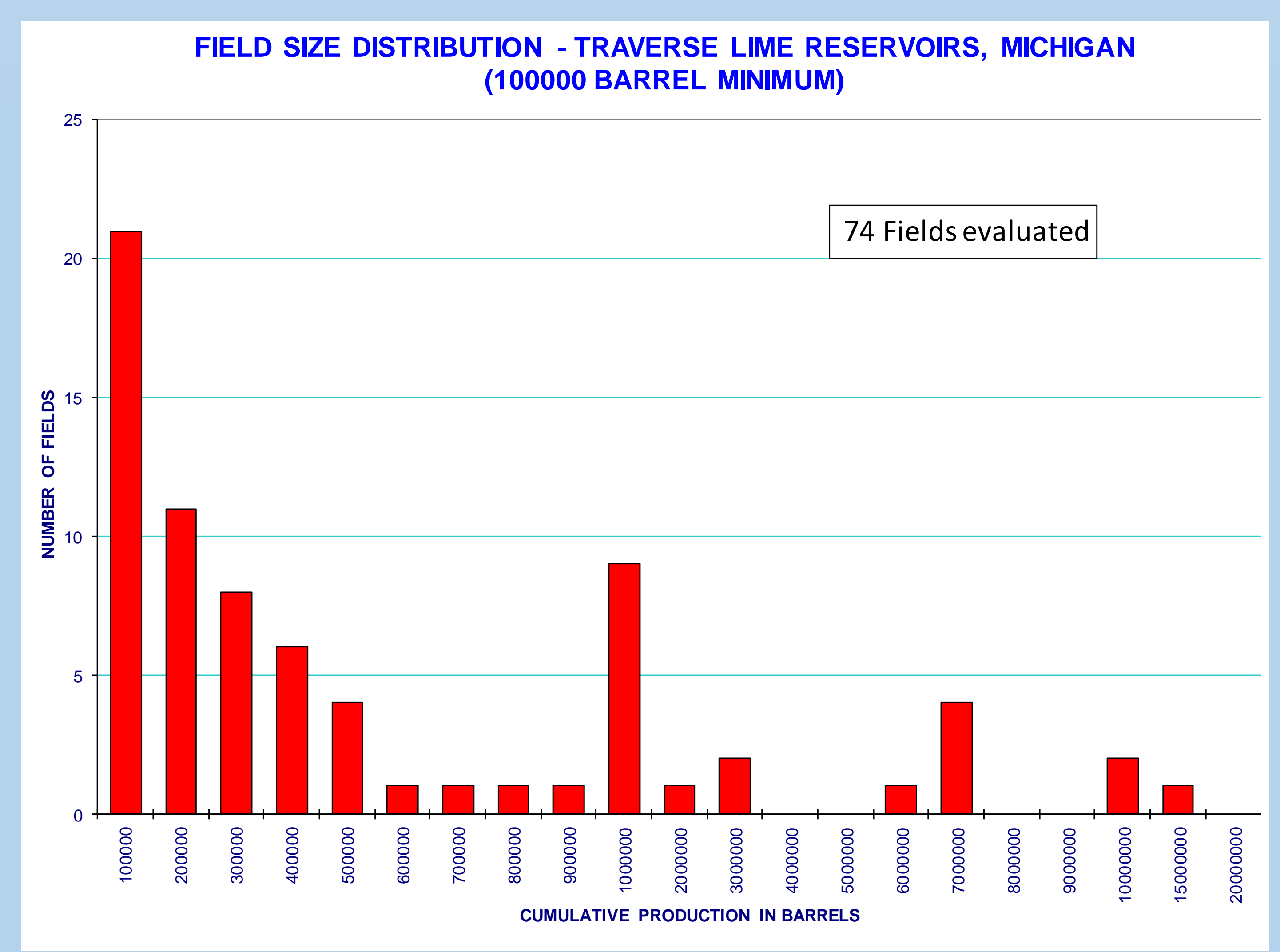

Figure 12: Traverse Fields show a skewed distribution with a significant number of fields producing less than 500,000 barrels of Oil and fewer fields producing more than 6,000,000 barrels. Large fields dominate the cumulative production from the Traverse Group in Michigan.

Figure 13: Traverse Fields exhibit strong decline curves initially, but continue to produce for many years. The Jefferson Field was re-drilled at closer spacing - generating the second peak in production. 